\title{
Heritability of floral traits for the perennial wild flower Penstemon centranthifolius (Scrophulariaceae): clones and crosses
}

\author{
RANDALL J. MITCHELL* \& RUTH G. SHAW $\dagger$ \\ Department of Biology and Department of Botany and Plant Sciences, University of California, Riverside \\ CA 92521, U.S.A.
}

\begin{abstract}
Floral and reproductive traits frequently influence pollinator behaviour and plant reproductive success and are therefore thought to be under selection. However, for wild plant populations there is little information on the amount of genetic variation for such traits. We estimated broad- and narrow-sense heritability of floral and reproductive traits for two populations of the perennial wildflower Penstemon centranthifolius, using a paternal half-sib crossing design in one case, and clonal propagation of ramets from different genets in the other. In both designs, most traits were significantly heritable, including nectar production, corolla length and width, inflorescence length and total flower production. Flowering date was significantly heritable for the crosses, but not for the clones, while nectar sugar concentration was not significantly heritable in either design. Genetic correlations were in some cases strong, and in some cases differed greatly from the corresponding phenotypic correlations. These results indicate that $P$. centranthifolius harbours a large reservoir of genetic variance which could support an evolutionary response to phenotypic selection.
\end{abstract}

Keywords: genetic correlation, heritability, maximum-likelihood, nectar, Penstemon centranthifolius, reproduction.

\section{Introduction}

Many recent studies indicate that components of plant fitness can be influenced by variation in traits such as flower number, flower size, stigma exsertion, nectar concentration, and nectar production rate (Stanton et al., 1986; Wyatt \& Shannon, 1986; Campbell, 1989; Galen \& Stanton, 1989; Broyles \& Wyatt, 1990; Real \& Rathcke, 1991; Campbell et al., 1991; Cresswell \& Galen, 1991; Mitchell, 1993). Such studies reveal much about the nature and magnitude of phenotypic selection but most do not explore the genetic basis of observed variation. In outcrossing species an evolutionary response to selection is not expected unless there is additive genetic variance for those traits (Falconer, 1981).

In this paper we estimate the genetic basis for variation in floral and reproductive traits for one angiosperm species, using two different techniques. First, we estimate additive genetic variation and narrow-sense

*Correspondence: Department of Biology, University of New Mexico, Albuquerque, NM 87131, U.S.A.

$\dagger$ Present address: Department of Ecology, Evolution and Behavior, University of Minnesota, St. Paul MN 55108, U.S.A. heritability, as well as genetic covariance using a nested paternal half-sib crossing design. Second, we assess genetic variance and broad-sense heritability using clonal propagation of genets (genetically distinct individuals). This latter approach tends to overestimate the genetic influence of traits because genetic and nongenetic effects on observed phenotypes are confounded. For this reason 'clonal repeatability', as measured in this second experiment sets an upper bound on narrow-sense heritability (Falconer, 1981).

\section{Materials and methods}

Penstemon centranthifolius (Scrophulariaceae) is a common short-lived perennial of southern and coastal California (U.S.A.), and is primarily an early colonizer of disturbed areas such as recent burns and roadsides (Munz \& Keck, 1959). Dense and extensive flowering populations frequently appear 2-5 years after a disturbance, then decline, although permanent populations also occur. Flowering plants produce one to more than 30 inflorescences and often more than 1000 flowers in a season. On each inflorescence, one to 25 red tubular flowers are open simultaneously, each 
secreting copious amounts of dilute nectar $(\sim 20 \mu \mathrm{l}$ of $\sim 25$ per cent sucrose $/ 24 \mathrm{~h} /$ flower) at a constant rate (R. J. Mitchell, unpublished data). The hermaphroditic flowers are self-compatible and protandrous, spending approximately 1 day in male phase and 2 subsequent days in female phase (Mitchell, 1989). Floral morphology and nectar production rate are variable within and among populations (Straw, 1955). Flowering occurs primarily during March to July at elevations up to $2000 \mathrm{~m}$

Hummingbirds and native and introduced bees are common visitors and important pollinators of $P$. centranthifolius in the mountains of southern California where this study was conducted (Straw, 1955, 1957; Mitchell, 1989). Hummingbird pollinators preferentially visit plants with many flowers and high nectar production rates (R. J. Mitchell et al., unpublished data) indicating a potential for phenotypic selection on those traits. Thus, information on genetic contributions to variance in these traits will be valuable in assessing the expected response to selection.

\section{Crosses}

During summer 1988 (17 June to 19 July) flowering $P$. centranthifolius plants were haphazardly chosen from a $60 \times 200 \mathrm{~m}$ population on a disturbed, exposed ridge near Idyllwild, CA, U.S.A. (1600 m elevation). Plants were crossed in a nested half-sib design, with 29 male plants acting as exclusive pollen donors for each of two to four maternal plants. All crosses were carried out in the field, where plants were bagged with fine-mesh netting, and corollas were removed from immature buds to prevent selfing. Pollen was applied by rubbing dehisced anthers from paternal plants onto receptive stigmatas. Of 921 flowers on 88 plants crossed in this manner, 133 fruits on 55 plants produced at least one undamaged seed (this low fruit set is typical for naturally pollinated flowers as well; Mitchell, 1989). The realized initial family structure is shown in the first column of Table 1.

Seeds from these crosses were planted in a randomized block design at the University of California Riverside (300 m elevation) in November 1988. Each block consisted of a flat of individual $4 \mathrm{~cm}$ diameter $\times 8 \mathrm{~cm}$ deep planting cells filled with a mixture of soil mix and perlite. Each cell received a single randomly chosen seed, and only one seed per mother-father combination (henceforth referred to as a 'cross') was present in any one block. Therefore as many as 55 seeds (the number of maternal sibships) were placed in each block. Seed production from each cross was variable, but all viable seeds (up to a total of 40 , one for each block) from each cross were planted. As seed supplies from crosses producing few seeds were exhausted, the cell assigned to that cross was left empty.

Flats were kept on two benches in a greenhouse with natural photoperiod. The first seedlings emerged within 2 weeks, and most emerged during November 1988 to January 1989. Emergence overall was $\sim 40$ per cent (Table 1). Although some unemerged seeds may have been inviable, dormancy also occurs (R. J. Mitchell, personal observation). Plants were fertilized periodically throughout the study, and blocks were rerandomized on benches once a week while plants were in the greenhouse. Substantial seedling mortality $(\sim 40$ per cent) occurred during January because plants received too little water. This unplanned stress may have increased realism, as severe drought is common in the wild.

Table 1 Family structure at different stages of seedling growth, and at the time of trait measurement (1990-91)

\begin{tabular}{|c|c|c|c|c|c|}
\hline \multirow[b]{2}{*}{ Family type } & \multicolumn{3}{|l|}{1989} & \multicolumn{2}{|l|}{$1990-91$} \\
\hline & Planted & Emerged & Alive at 1 year & Flowering & Nectar \\
\hline One mother per father & 12 & 13 & 12 & 12 & 12 \\
\hline Two mothers per father & 8 & 6 & 6 & 6 & 5 \\
\hline \multirow[t]{2}{*}{ Three mothers per father } & 9 & 4 & 3 & 2 & 2 \\
\hline & - & - & - & - & - \\
\hline Total paternal sibships & 29 & 23 & 21 & 20 & 19 \\
\hline Total maternal sibships & 55 & 37 & 33 & 30 & 28 \\
\hline Total progeny & 1043 & 405 & 232 & 179 & 137 \\
\hline
\end{tabular}

Values are number of families of each type (along with total).

The total progeny indicates the total number of individuals across all family types at any one time, or for any one type of measurement. 
During April 1989 all seedlings were transplanted to $10 \times 10 \mathrm{~cm}$ pots and moved to an outdoor lathhouse. Blocks were thereafter re-randomized approximately once a month. Plants were moved to $15 \times 15 \mathrm{~cm}$ pots in October 1989. The first flowers on these plants appeared in late February 1990, with the bulk of flowering in April and May.

To assess genetic variability, we considered both vegetative traits expressed early in life and traits related to reproduction. In October 1989 three vegetative characters were measured: length and width of the largest leaf, and length of the longest branch. Floral morphology was measured on four separate dates during 1990 and seven dates during 1991. On each inflorescence (many plants produced more than one inflorescence in any one year) one flower was measured on each date, always the lowest flower in female phase. For each flower, corolla length (from base of sepals to opening of corolla tube), corolla width (horizontal inside diameter), and gynoecium length (from base of sepals to tip of stigma) were measured with calipers. Stigma exsertion was calculated as the difference between corolla length and gynoecium length for each flower. Nectar traits were measured on two dates in 1990, and eight dates in 1991. To do this, for all available inflorescences a cap was placed over a single bud likely to open the next morning (hummingbirds frequently visited flowers on these lathhouse plants, and capping prevented birds from removing nectar). Twenty-four hours later the volume and concentration (percentage mass/total mass) of the accumulated nectar was measured using microcapillary tubes and a refractometer. This method provides a good estimate of $24 \mathrm{~h}$ nectar production rate $(\mathrm{R}$. J. Mitchell, unpublished data). Total sugar production was calculated from volume and concentration following Bolten et al. (1979). After flowering for each year was completed, the length of each inflorescence and total flower production for each plant were measured, ignoring those plants which produced no flowers in either year (analysis including non-flowering plants provides qualitatively similar results $)$.

We analysed overall plant means for each trait except total flower production, for which the total over the 2 years of the study was analysed. Nectar traits differed strongly among dates, so we first performed an ANOvA using sampling date as a class variable, then performed the genetic analysis on the plant mean of the residuals. Qualitatively similar results follow from analysis of plant means of raw values. Similarly, date of first flowering varied among years, so we analysed plant means of the residual deviations from the mean for each year. Plant means for all traits were normally distributed, or could be transformed to approximate normality (see Table 2 for transformations). Because sample size for many traits is relatively small, our ability to detect significant $V_{\mathrm{a}}$ is low, and only strong effects are likely to be detected.

Estimates of heritability and additive genetic variance $\left(V_{\mathrm{a}}\right)$ were obtained using a restricted maximum likelihood (REML) estimation program described in Shaw (1987; see also Shaw \& Shaw, 1992), which can accommodate unbalanced designs such as ours. In contrast to the nested analysis of variance typically used for analysing data in this design, maximum likelihood methods readily accommodate unbalanced designs such as ours. Although our original design was adequate to estimate additive, dominance (or maternal), and environmental variance $\left(V_{\mathrm{e}}\right)$, we obtained negative estimates of dominance variance for most traits when the full model was fitted. This is commonly attributable to sampling variance, and suggests that the true dominance variance is zero (Hill \& Thompson, 1978). We therefore estimated only $V_{\text {a }}$ and $V_{\mathrm{e}}$. Block effects were in no case significant, and for simplicity were not considered, or included in the model.

\section{Clones}

We also estimated genetic influences on the reproductive traits described above by cloning eight genets taken from a natural population near Anza, CA, U.S.A. (1340 m elevation), $20 \mathrm{~km}$ east of the Idyllwild site. Plants were transplanted from the field in Autumn 1987 (we were careful to include only single genets), and in November 1989 four single rooted branches from each genet were separated, and the $10 \mathrm{~cm}$ branches (ramets) were placed separately in $15 \times 15$ $\mathrm{cm}$ pots. The 32 pots were kept in a lathhouse and randomized on the bench approximately once a month. One ramet died shortly after division, and is not included in the analysis, but all others survived through June 1991.

Floral traits were measured for these plants as described above for the crossing experiment, on three separate dates in 1990, and six dates in 1991. Nectar traits were measured on two dates in 1990 and seven dates in 1991. Plant means for each trait were analysed using a nested ANOVA, ramets nested within genets. Genetic variance $\left(V_{\mathrm{g}}\right)$ was estimated as:

$V_{\mathrm{g}}=\left(\mathrm{MS}_{\text {Genets }}-\mathrm{MS}_{\text {Ramets }(\text { Genets })}\right) / r$,

where $\mathrm{MS}=$ mean square, and $r=$ mean number of ramets measured/genet (Falconer, 1981). Clonal repeatability, an estimate of broad-sense heritability (Falconer, 1981) was estimated as $V_{\mathrm{g}} / V_{\mathrm{p}}$, where $V_{\mathrm{p}}=$ phenotypic variance $=$ total variance. 
Table 2 Heritability of plant means from the crosses using restricted maximum likelihood

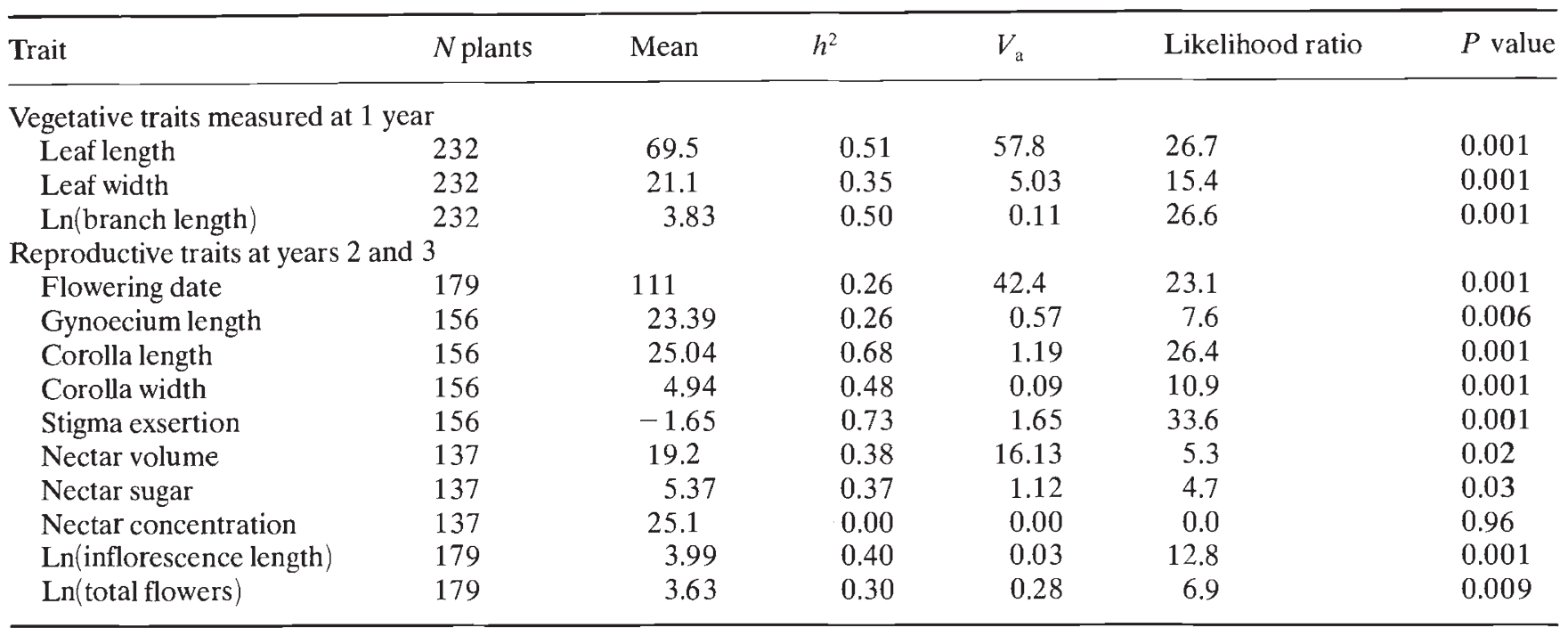

For corolla length and width $N$ flowers $=629$; for gynoecium length and stigma exsertion $N$ flowers $=616$; and for nectar traits $N$ flowers $=347$.

Flowering date is in days since 1 January of each year, measures of size in mm, volume in $\mu \mathrm{l}$, sugar in mg sucrose equivalents, and concentration in \% mass/mass.

Significance of $V_{\mathrm{a}}$ was tested by comparing a model with $V_{\mathrm{a}}$ and $V_{\mathrm{e}}$ free to vary with a model constraining $V_{\mathrm{a}}$ to zero; the resulting likelihood ratio is compared to $\chi^{2}, 1$ d.f.

For both designs, the relatively uniform environment experienced by plants in the lathhouse may have decreased $V_{\mathrm{e}}$, and therefore may have inflated our estimates of heritability (as $V_{\mathrm{p}}=V_{\mathrm{g}}+V_{\mathrm{e}}$ ). However, little is known of the genetic basis of the attributes considered here (especially nectar traits), and we therefore are primarily interested in whether there is any genetic component to interplant variation, as a first step towards understanding the adaptive significance of these traits. Use of a standardized environment maximizes our chances of detecting genetic components of variation. Another potential complicating factor in interpreting our results is that heritability estimates in the relatively novel environment of the lathhouse may be inflated if there are substantial genotype $\times$ environment interactions (Mitchell-Olds \& Rutledge, 1986). However, because $P$. centranthifolius is primarily a colonizing species, genetic parameter estimates for novel environments probably are relevant, as this species frequently colonizes novel locations.

\section{Results}

\section{Crosses}

All but one of the traits considered in the crossing experiment showed significant additive genetic variance and narrow-sense heritability (Table 2). The largest heritability estimate was 0.73 for stigma exsertion, and the lowest was -0.002 for nectar concentration (not significantly different from zero). Phenotypic and genetic correlations for reproductive traits are presented in Table 3. Although many genetic correlations are substantial, our sample size was not large enough to detect significant genetic correlations smaller than an absolute value of $\sim 0.8$. Some genetic correlation estimates were not in the range of -1 to +1 , or could not be estimated because of a negative estimate of $V_{\mathrm{a}}$. These anomalies occur most commonly for nectar concentration, and the very low heritability of this trait probably contributed to these inadmissable values. Genetic and phenotypic correlations were not strongly associated with one another, as measured by the mean absolute difference between the genetic and phenotypic correlations (Willis et al., 1991; mean \pm s.d. $=0.33 \pm 0.36, N=40)$, and by the correlation between elements of the two matrices (Pearson product-moment $r=0.36, N=40$ ).

\section{Clones}

As with the crosses, the clones exhibited strong genetic variance for most measured traits (Table 4). The largest broad-sense heritability was 0.94 for corolla width, and the lowest was 0.04 for nectar concentration. In contrast to results from the crosses, $V_{\mathrm{g}}$ for flowering 
Table 3 Phenotypic and genetic correlations for reproductive traits from the crosses. Phenotypic correlations are above the diagonal, genetic correlations are below the diagonal

\begin{tabular}{lccccccccrr}
\hline & FD & GL & CL & CW & \multicolumn{1}{l}{ SE } & NV & NS & NC & IL & TF \\
\hline Flowering date & - & 0.00 & $\mathbf{0 . 1 9}$ & 0.15 & $-\mathbf{0 . 1 6}$ & 0.10 & 0.09 & -0.05 & -0.20 & $-\mathbf{0 . 5 4}$ \\
Gynoecium length & -0.37 & - & $\mathbf{0 . 4 2}$ & -0.02 & $\mathbf{0 . 6 1}$ & 0.07 & 0.11 & 0.10 & -0.04 & 0.06 \\
Corolla length & 0.12 & 0.07 & - & 0.09 & -0.45 & 0.03 & 0.02 & -0.04 & 0.11 & -0.05 \\
Corolla width & 0.04 & $-\mathbf{1 . 0 9}$ & -0.34 & - & -0.09 & 0.12 & 0.13 & -0.04 & $-\mathbf{0 . 1 7}$ & -0.07 \\
Stigma exsertion & -0.33 & 0.52 & $-\mathbf{0 . 8 1}$ & -0.33 & - & 0.04 & 0.08 & 0.13 & 0.04 & 0.11 \\
Nectar volume & $\mathbf{0 . 8 5}$ & 0.14 & 0.30 & 0.18 & -0.07 & - & $\mathbf{0 . 9 7}$ & $-\mathbf{0 . 3 9}$ & 0.14 & 0.06 \\
Nectar sugar & 0.61 & 0.16 & 0.29 & -0.09 & -0.10 & 1.00 & - & -0.20 & 0.13 & -0.04 \\
Nectar concentration & $\bullet$ & -0.12 & $\mathbf{1 . 7 5}$ & -0.22 & -1.03 & $\bullet$ & $\bullet$ & - & -0.05 & -0.19 \\
Ln(inflorescence length) & - & -0.16 & -0.00 & 0.01 & 0.03 & 0.03 & -0.22 & $\bullet$ & - & $\mathbf{0 . 4 1}$ \\
Ln(total flower) & -0.52 & 0.21 & -0.58 & -0.05 & 0.62 & -0.56 & -0.43 & 0.76 & 0.13 & - \\
\hline
\end{tabular}

Abbreviations are the first letters of each trait name.

Boldface values are significantly different from zero. For phenotypic correlations significance was assessed using a $t$-test, and for genetic correlations by comparing a model allowing genetic correlation with one that does not. Some estimated genetic correlations have absolute values $>1$, probably indicating that the true correlations are near 1 or $-1 .(\bullet)$ Genetic correlations that could not be estimated.

date was not significantly greater than zero. Broadsense heritability measured in this experiment was greater than narrow-sense heritability in the crossing experiment for all but two of 10 traits (flowering date and stigma exsertion). The sample size of genets (eight) was too small to allow reliable estimation of genetic correlations.

\section{Discussion}

Our results indicate that $P$. centranthifolius harbours a large reservoir of genetic variance in floral, reproductive and vegetative traits (Tables 2 and 4), and that a large fraction of that variance is additive (Table 2). This result agrees with studies of other wild plant species (e.g. Shore \& Barrett, 1990; Mazer \& Schick, 1991), and supports the idea that $P$. centranthifolius has the genetic capability to respond to selection on those traits. Documentation of the patterns of inheritance for wild plants is rare and difficult because of the long time required for many species to reach reproductive age, the large sample sizes required for statistically meaningful measurements, and the mathematical problems that follow from the unbalanced designs common for such studies. Indeed, given the severe imbalance of our data, analysis by standard procedures is questionable, but this imbalance poses no difficulty for REML estimation.

To our knowledge, neither heritability nor genetic determination of nectar production rate has previously been measured for a wild plant species (see Rathcke, 1992). For crop plants, especially alfalfa (Medicago sativa), there is more evidence (Pedersen, 1953; Hawkins, 1971; Walker et al., 1974; Teuber \& Barnes, 1979; Teuber et al., 1990). Nectar production rate frequently varies strongly with abiotic factors (e.g. Kenoyer, 1917; Pleasants, 1983; Zimmerman, 1983; Plowright, 1987; D. C. Campbell \& K. J. Halama, unpublished data), and such large environmental influences might be expected to mask any heritable variation. Our results argue against the generality of that inference, and bolster the argument that phenotypic selection might influence the evolution of nectar production rate (Zimmerman, 1988; Mitchell, 1993). However, our plants were grown under relatively uniform conditions, and so might exhibit greater genetic determination of realized phenotype than in the wild. Nonetheless, the range of nectar production seen here is similar to that in wild populations (R. J. Mitchell, unpublished data), implying that there may be little disparity between $V_{\mathrm{e}}$ in the field and in this study.

In contrast to nectar volume and sugar production, nectar concentration exhibited no detectable genetic determination in either of our experiments. This may in part be a result of the minimal phenotypic variation among plants; the coefficient of variation of concentration for the clones was only 2.7 per cent, and for the crosses was 13.8 per cent (such low coefficients of variation for plant mean concentration are common for $P$. centranthifolius plants in the field as well, e.g. 12.1 per cent, $N=45 ; \mathrm{R}$. J. Mitchell, unpublished data). However, the question of why there is so little variation (even for the crosses) still remains. A possible explanation involves selection by pollinators, as inferred from 
Table 4 Estimates of clonal repeatability using plant (i.e. ramet) means

\begin{tabular}{lccccccc}
\hline Trait & Mean & & $h^{2}$ & $V_{\mathrm{g}}$ & $F$ & $P$ value & d.f. \\
\cline { 6 - 8 } Flowering date & 107 & 0.06 & 7.4 & 1.2 & 0.3 & 7,23 \\
Gynoecium length & 24.23 & 0.49 & 0.78 & 4.3 & 0.004 & 7,22 \\
Corolla length & 25.71 & 0.86 & 1.68 & 15.0 & 0.0001 & 7,22 \\
Corolla width & 4.60 & 0.94 & 0.20 & 24.0 & 0.0001 & 7,22 \\
Stigma exsertion & -0.24 & 0.68 & 1.46 & 7.6 & 0.0002 & 7,22 \\
Nectar volume & 23.8 & 0.53 & 14.0 & 4.0 & 0.01 & 7,16 \\
Nectar sugar production & 6.40 & 0.47 & 0.75 & 3.4 & 0.02 & 7,16 \\
Nectar concentration & 23.8 & 0.04 & 0.04 & 1.1 & 0.4 & 7,16 \\
Ln(inflorescence length) & 4.47 & 0.60 & 0.05 & 5.8 & 0.0008 & 7,21 \\
Ln(total flowers) & 3.90 & 0.68 & 0.72 & 7.6 & 0.0001 & 7,21 \\
\hline
\end{tabular}

For morphology, total $N$ flowers $=134$; for nectar traits, $N$ flowers $=79$.

All sizes are in mm, sugar production is in $\mu \mathrm{l}$ and mg sucrose equivalents, and concentration is in \% wt/wt. Inflorescences of some plants were damaged before

final measurements, decreasing sample size for inflorescence length and total

flowers.

$V_{\mathrm{g}}$ includes all effects shared by ramets of the same genet. $F$ ratios are for significance of differences among genets, tested over $\mathrm{MS}_{\text {ramets(genets) }}$.

floral syndromes (Faegri \& van der Pijl, 1971). One such syndrome is that of 'hummingbird pollination', a cardinal characteristic of which is secretion of copious amounts of relatively dilute nectar. Following this line, one explanation for the minimal genetic variation for nectar concentration is canalization of an 'optimal concentration' (see Pyke \& Waser, 1981). In agreement with this idea, genetic variation in concentration for bee-pollinated alfalfa plants also is limited, with a coefficient of variation of 1.8 per cent (Shuel, 1952). It also is possible that these plant species could be at a biological limit, such that no meaningful variation among genotypes in nectar concentration is possible given their genetic, morphological and physiological make-up. Unfortunately, we currently have little data with which to assess these speculations. Investigation of the reaction norm of nectar concentration as a function of water availability might be one useful approach.

The substantial mortality experienced during this experiment might have affected estimates of heritability by decreasing sample size (and therefore precision), decreasing the range of genetic variation present in the survivors, or causing selection on traits correlated with those measured later. The latter two possibilities would tend to decrease, rather than increase, heritability estimates (Meyer \& Thompson, 1984), and so do not alter our conclusions.

Despite the spatial separation of these populations, and the different techniques used to estimate broadand narrow-sense heritability, there is reasonable concordance between them. This is in accord with (i) the idea that both populations have similar heritabilities, and (ii) the theoretical expectation that narrow-sense heritabilities are smaller than broad-sense heritabilities (Falconer, 1981). Indeed, estimates of genetic determination were greater for the clones than for the crosses in all but two cases. The exceptions are flowering date and stigma exsertion. These exceptions may result from sampling error, or from actual differences in genetic variability between populations.

When predicting the response of traits to phenotypic selection, the genetic correlation matrix is required, as direct selection on one trait might affect the trajectory of genetically correlated traits (Falconer, 1981; Lande \& Arnold, 1983). Estimation of genetic correlations is difficult, but vital for such prediction; for $P$. centranthifolius, we found little correspondence between the genetic and phenotypic correlation matrices. This result is in accord with the caution of Willis et al. (1991), that inferring phenotypic from genetic correlations, although tempting, is ill-advised. Our design was too small to reliably estimate whether genetic correlations deviate significantly from zero except in the most obvious of cases, but our estimates are nonetheless unbiased, and therefore are useful for this comparison of magnitudes.

Our results from these clones and crosses showed qualitative agreement on the extent of genetic determination of many traits likely to be important in the biology of $P$. centranthifolius. The much smaller sample sizes required for estimating clonal repeatability make it an attractive alternative to an extensive 
crossing experiment. We do not advocate use of clonal repeatability as the sole means of assessing genetic determination, because this approach confounds genetically determined variation that supports selection response with variation from other causes, such as environmentally-induced maternal effects. However, in this particular case few conclusions about heritability would have been altered if the clones alone had been considered.

\section{Acknowledgements}

We thank Karen Mitchell, Nick Waser, Arlee Montalvo, Steve Morgan, Andy Sanders, Robert Podolsky, Ann Evans, Iva and Joe Lubin, and two anonymous reviewers for help in the field, help measuring traits, valuable advice, and suggestions on the manuscript. Bill Hauser kindly allowed us to remove plants from his property. Len Nunney and David Reznick encouraged us to include study of clones. The USFS provided permission to work on public lands, and lathhouse space was provided by the Department of Biology and the Department of Botany and Plant Sciences at the University of California Riverside. Supported by grants from the California Native Plant Society, the Chapman Fund of the American Museum of Natural History, the Hardman Fund for Evolution and Conservation Study, the Newell Fund of the University of California Riverside, the Riverside-San Bernardino Audubon Society, and the Southern California Botanists.

\section{References}

BOLTEN, A. B., FEINSINGER, P., BAKER, H. G. AND BAKER, I. 1979. On the calculation of sugar concentration in flower nectar. Oecologia, 41, 301-304.

BROYLES, S. B. AND WYATT, R. 1990. Paternity analysis in a natural population of Asclepias exaltata: multiple paternity, functional gender, and the 'pollen donation hypothesis'. Evolution, 44, 1454-1468.

CAMPBELL, D. C. 1989. Measurements of selection in a hermaphroditic plant: variation in male and female pollination success. Evolution, 43, 318-334.

CAMPBEll, D. C., WASER, N. M., PRICE, M. V., LYNCH, E. A. AND MITCHELL, R. J. 1991. A mechanistic analysis of phenotypic selection: pollen export and corolla width in Ipomopsis aggregata. Evolution, 45, 1458-1467.

CRESSWELL, J. E. AND GALEN, c. 1991. Frequency-dependent selection and adaptive surfaces for floral character combinations: the pollination of Polemonium viscosum. Am. Nature, 138, 1342-1353.

FAEGRI, K. AND VAN DER PIJL, L. 1971. The Principles of Pollination Ecology, 2nd rev. edn. Pergamon, Oxford.

FALCONER, D. S. 1981. Introduction to Quantitative Genetics, 2nd edn. Longman, New York, pp. 115-181.
GALEN, C. AND STANTON, M. L. 1989. Bumble bee pollination and floral morphology: factors influencing pollen dispersal in the alpine sky pilot Polemonium viscosum (Polemoniaceae). Am. J. Bot., 76, 419-426.

HAWKINS, R. P. 1971. Selection of height of nectar in the corolla tube of English singlecut red clover. J. Agric. Sci., 77, 351-361.

HILl, W. G. AND THOMPSON, R. 1978. Probabilities of nonpositive definite between group or genetic covariance matrices. Biometrics, 34, 429-439.

KENOYER, L. A. 1917. Environmental influences on nectar secretion. Bot. Gaz., 63, 249-265.

LANDE, R. AND ARNOLD, S. J. 1983. The measurement of selection on correlated characters. Evolution, 37, 1210-1226.

MAZER, S. J. AND SCHICK, C. T. 1991. Constancy of population parameters for life-history and floral traits in Raphanus sativus L. II. Effects of planting density on phenotype and heritability estimates. Evolution, 45, 1888-1907.

MEYER, K. AND THOMPSON, R. 1984. Bias in variance and covariance component estimators due to selection on a correlated trait. Sonderdruck aus Zeitschrift für Tierzüchtung und Züchtungsbiologie Bd., 101, 33-50.

MITCHell, R. J. 1989. Is Penstemon centranthifolius truly hummingbird pollinated? Cromosoma, 15, 1-9.

MITCHELL, R. J. 1993. Adaptive significance of Ipomopsis aggregata nectar production rate: observational and experimental studies in the field. Evolution, 47, 25-35.

MITCHELL-OLDS, T. AND RUTLEDGE, J. J. 1986. Quantitative genetics in natural plant populations: a review of the theory. Am. Nature, 127, 379-402.

MUNZ, P. A. AND KECK, D. D. 1959. A California Flora. University of California Press, Berkeley.

PEDERSEN, M. W. 1953. Seed production in alfalfa as related to nectar production and honeybee visitation. Botanical Gazette, 115, 124-138.

PLEASANTS, J. M. 1983. Nectar production patterns in Ipomopsis aggregata (Polemoniaceae). Am. J. Bot., 60, 1468-1475.

PLOWRIGHT, R. C. 1987. Corolla depth and nectar concentration: an experimental study. Can. J. Bot., 63, 1011-1113.

PYKE, G. H. AND WASER, N. M. 1981. The production of dilute nectars by hummingbird and honeyeater flowers. Biotropica, 13, 260-270.

RATHCKE, B. J. 1992. Nectar distributions, pollinator behaviour, and plant reproductive success. In: Hunter, M. D., Ohgushi, T. and Price, P. W. (eds.) Effects of Resource Distribution on Animal-Plant Interactions, Academic Press, New York, pp. 113-138.

REAL, L. A. AND RATHCKE, B. J. 1991. Individual variation in nectar production and its effects on fitness in Kalmia latifolia. Ecology, 72, 149-155.

SHAW, R. G. 1987. Maximum-likelihood approaches applied to quantitative genetics of natural populations. Evolution, 41, 812-826.

SHAW, R. G. AND PLANTENKAMP, G. A. J. (1993). Quantitative genetics of response to competitors in Nemophila menziesii: a greenhouse study. Evolution (in press).

SHAW, R. G. AND SHAW, F. H. 1992. Quercus: programs for quantitative genetic analysis using maximum likelihood. 
Published electronically on Internet, available via anonymous ftp from ftp.bio.indiana.edu; directory path biology/ quantgen/quercus.

SHORE, J, S. AND BARRETT, S. C. H. 1990. Quantitative genetics of floral characters of homostylous Turnera ulmifolia var. angustifolia Willd. (Turneraceae). Heredity, 64, 105-112.

SHUEL, R. W. 1952. Some factors affecting nectar secretion in red clover. Plant Physiol., 57, 95-110.

STANTON, M. L., SNOW, A. A. AND HANDEL, S. N. 1986. Floral evolution: attractiveness to pollinators increases male fitness. Science, 232, 1625-1627.

STRAW, R. M. 1955. Floral ecology and evolution in Penstemon. Ph.D. thesis, Rancho Santa Ana Botanic Garden, Claremont, CA.

STRAW, R. M. 1957. Adaptive morphology of the Penstemon flower. Evolution, 11, 112-119.

TEUBER, L. R. AND BARNES, D. K. 1979. Environmental and genetic influences on alfalfa nectar. Crop Sci., 19, 874-878.
TEUBER, L. R., RINCKER, C. M. AND BARNES, D. K. 1990. Seed yield characteristics of alfalfa populations selected for receptable diameter and nectar volume. Crop Sci., 30, 579-583.

WALKER, A. K., BARNES, D. K. AND FURGALA, B. 1974. Genetic and environmental effects on quantity and quality of alfalfa nectar. Crop Sci., 14, 235-238.

WILLIS, J. H., COYNE, J. A. AND KIRKPATRICK, M. 1991. Can one predict the evolution of quantitative characters without genetics? Evolution, 45, 441-443.

WYATT, R. AND SHANNON, T. R. 1986. Nectar production and pollination of Asclepias exaltata. Syst. Bot., 11, 326-334.

ZIMMERMAN, M. 1983. Plant reproduction and optimal foraging: experimental nectar manipulations in Delphinium nelsonii. Oikos, 41, 57-63.

ZIMMERMAN, M. 1988. Nectar production, flowering phenology, and strategies for pollination. In: Lovett-Doust, $\mathrm{J}$. and Lovett-Doust, L. (eds) Plant Reproductive Ecology, Patterns and Strategies, Oxford University Press, Oxford, pp. 157-178. 